\title{
Foam Field Tests: State of the Art and Critical Review
}

\author{
* Castanier L. M., ** Hanssen J. E. \\ * Stanford - University, U.S.a. \\ ** RF - Rogaland Research, Norway
}

\begin{abstract}
Copyright 1895, Steering Committee of the European 1OR - Sympotium.
This paper was presented at the 8th. European IOR - Symposium in Vienna, Austria, May 16 - 17, 1995

This paper was selected for presentation by the Steering Committee, following review of infomation contained in an abstract

abmitted by the author(e). The paper, as presented has not been reviewed by the stearing committee.
\end{abstract}

\begin{abstract}
This paper gives a current overview of field experience with the use of foam for improved recovery and a critical evaluation of selected pilot projects. The focus is on identifying and describing critical problems encountered in foam tests and suggesting improvements.
\end{abstract}

Foam applications are classified by the type of gas injected and the type of foam process. This is important since the choice of foamer is process dependent as well as reservoir dependent. The processes evaluated include the use of foam in cyclic steam, steam drive, $\mathrm{CO}_{2}$ drive, hydrocarbon-gas/nitrogen diversion and in-depth mobility control, GOR-control treatment of production wells. and water diversion treatment. The reservoir aspect ratio is a useful parameter for comparing foam process varieties and understanding the different application environments.

The use of foam in conjunction with steam is a mature and proven technology that, even at current oil prices, can be applied in many fields at an attractive cost over that of steam. A key question addressed by this paper is how the positive experience with foam can be successfulty transferred to other gases, for which results are more mixed.

Many technical failures are explainable by erroneous problem definition. Either the reservoir cause of the production problem observed was not known, or an in itself viable foam process was applied to the wrong reservoir. In many cases, reservoir description was poor prior to the foam test, and insufficient data were collected during the test to obtain a clear picture of the effects of the foam. Interference from neighboring patterns or wells often cause problems with interpreting the effects of a foam treatment. The presence of fractures may have been the cause of several failed tests. Only in one case was a treatment procedure devised specifically to account for fractures, with encouraging results. A few early failures appear to have been due to use of thermally sensitive foamers. In some later tests, the choice of foamer appears less than optimal in view of later, comparable product selection efforts. A few projects were rated as technical successes but economic failures, but the cost of chemicals was generally not the cause of this problem. Production well treatments, which have been rarely used in the past, show definite possibilities for the near future.

\section{Introduction}

The combination of a gas and a foaming agent injected in a hydrocarbon reservoir can generate a foam. In broad terms, foam can be described as a continuous liquid phase surrounding a discontinuous gas phase. As the liquid network is composed of thin films reducing and sometimes even blocking the gas flow, this process can be applied to improved and enhanced oil recovery. Foam has been used to improve the injection of various gases, as a means of reducing coning and cusping in producers, to improve gas storage and in some cases to enhance waterflooding. Figure 1 illustrates the different problems with gas injection that foam can solve.

The practical oilfield experience with foam spans more than 25 years. Examination of the published literature shows a broad range of results, from total technical and economic failure to success. Closer examination of selected foam field tests allows some insight in the causes of the failures and should help better design future field projects. This paper does not pretend to be a comprehensive literature review, but rather attempts to describe some of the problems encountered during foam field tests, generalize some observations, and suggest possible improvement for the future. 


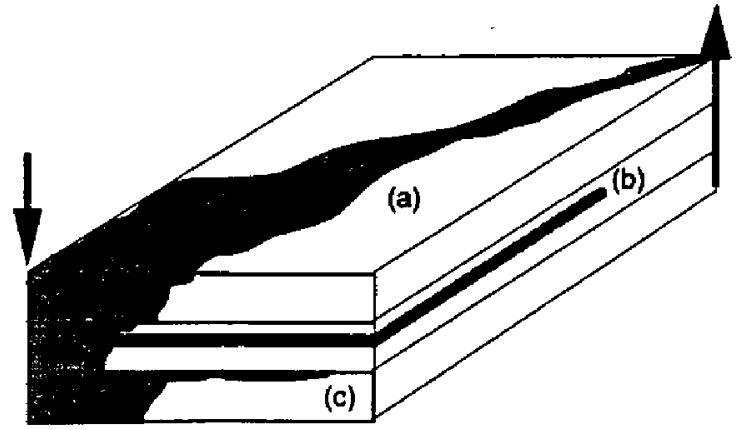

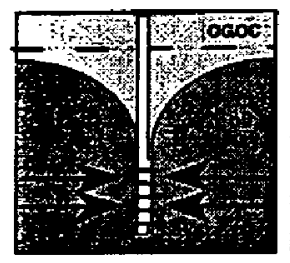

(d)

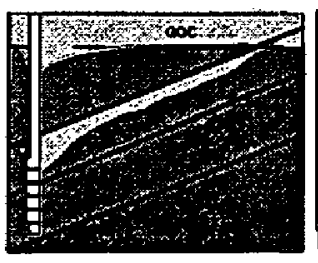

(e)

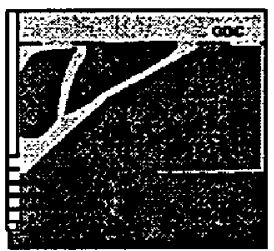

(f)
Fig. 1. Problems caused by high gas mobility. Top: gas injection; a) poor areal sweep, b) Gravity override. c) Gas channeling. Bottom: Near the producer; d) Gas coning, e) Gas cusping, f) Gas channeling in fractures. From ref. [1].

Different classifications of foam field projects can be used. One of the most useful is by type of gas injected and by process.

Among the drives (well-to-well methods), steam injection with foam is now a mature technology, routinely applied in the field. Injection of $\mathrm{CO}_{2}$ combined with foam, tested in some extent though much less than steam foam, has not met the same success and is still in the development stage. Few field cases of foam used with injected hydrocarbon gases or nitrogen are known and it is hard to generalize from these.

Cyclic steaming with foams is a proven technique used in thousands of wells, though published data on these are scarce.

Production well treatment show definite possibilities for the near future. Examples of using foam to improve gas storage and waterflooding exist but are rarely well documented.

A key issue discussed in this work is the transfer of experience with foam technology from steam injection to other production processes and other reservoir classes.

\section{Problem definition}

Before trying any improved oil recovery method, an examination of the reservoir is needed. Foam use must be based on a careful examination of the problem to be solved as well as on proper reservoir description and evaluation. The type of foam properties desired witl vary depending on the process involved: deep mobility control, injectant blockage and diversion, or GOR con- trol. This point is addressed in a recent work [1] which summarizes the desired properties of foams to be used in these three main foam process types. Importantly, the choice of foamer system is process-dependent as well as reservoir dependent.

In order to properly define the problem to be solved, the engineer must use all available information. Geological and geophysical reservoir description as well as classic monitoring techniques must be combined with operator experience. As an example, a recent paper [2] includes a critical re-evaluation of an early, well documented foam project various reservoir description and monitoring methods as applied to a steam foam project. A similar approach must be used prior to and during any type of foam field test.

As we will see later, some so-called technical failures can be explained by erroneous problem definition. A process that in itself could have some merit was applied to the wrong reservoir. This is probably the single most significant cause of IOR project failures and, as such, deserves to be emphasised.

\section{Steam foam}

A compilation of field tests of steam with foam additives was made in 1989 [3]. even in today's low oil price environment, steam-foam technology has matured from development to large-scale commercial application in some oil- producing regions. Examples of recent developments are given by references [4-8].

\section{Cyclic steam}

Foam has been successfully used to improve cyclic steam injection. To date, foam has been used in over 5,000 cyclic stimulations [9]. Most of these projects are located in California but examples of successful cyclic steam foam can also be found in Venezuela [6] and in Canada. Since the operating conditions can vary, the type of foamer used depends of the conditions in each particular reservoir. Temperatures vary from $130^{\circ} \mathrm{C}$ to over $260^{\circ} \mathrm{C}$. One can obviously use cheaper, thermally less stable products at $130^{\circ} \mathrm{C}$ for a few days duration, but thermal stability is needed for projects such as in Venezuela [6] with high temperatures and long cycles.

Among the projects reviewed, some tests showed increased oil production without increased injection pressure. This could be caused by surfactant near-wellbore cleaning leading to wettability changes. Even if the surfactant used as a foamer is not thermally stable, decomposition products can lead to increased oil production. This was probably the case in several of the early tests. As oil tolerance has not been researched for most of the foamers routinely used in cyclic steam foam, the additional recovery above the cyclic steam method alone appears to be greater as the number of cycles increases. This observation is valid for most projects, but some tests exibit better improvement early in the life of the cycling. At this stage no explanation can be found. 
Cyclic steam foam is a proven, mature and economically sucessful technology. The cost/benefit ratio is low because of the low cost for the small amounts of foamer used and for added noncondensible gas (flue gases, or nitrogen produced by cost-effective membrane technology). The small amount of capital required above the steam costs make this technology attractive even at today low oil prices.

\section{Steam drives}

Many sucessful projects involving steam drives enhanced by foam can be found in the literature. Most of the unsucessful results can be attributed to several causes:

- Choice of a thermally unstable foamer. This was especially the case in early projects where laboratory screening was not adequate. Along the same line, surfactant loss via adsorption and partitioning into oil is an important factor that has not been studied in depth at steam drive conditions.

- Attempt to correct an impossible problem. Some examples are the presence of fractures and/or channels where the steam mobility could not be reduced by foam. Studies of foam in fractured media are rare, but it is generally considered that foam is less effective in fractures than in "normal" rock pores. The necessary regeneration of foam by snap-off, division of films and leave-behind is less favored in a fracture. Steam condensation makes the problem more accute than for non-condensible gases, where some blocking may result from preformed foam remaining in fractures.

- Last but not least, poor evaluation of oil in place at the start of a foam project leading to apparently poor recovery - of nonexisting oil. This is a major cause of many so called economic failures. The problem is often compounded by the difficulty of precisely measuring incremental production of heavy oil [2].

Despite these problems, most steam foam drive projects have in fact been technical and economic sucesses. The technology has matured to the point where the main problems remaining relate to optimization of foamer use and cost reductions. Many examples can be found of slug injection on varied schedules, attempts to compare the mobility reduction obtained with and without noncondensible gas added to the system, and a search for cheaper thermally stable foamers. It is curious to notice that optimization by useing foamers at low concentration has apparently not been field tried despite promising laboratory results [10]. Another possibility is to use sacrificial agents to take care of adsorption and partitioning before injecting a more expensive foamer.

\section{Foam in $\mathrm{CO}_{2}$ flooding}

The literature is less extensive on $\mathrm{CO}_{2}$ foam field projects than on steam foam projects. Only eight projects were reviewed in this study. The general impression is that $\mathrm{CO}_{2}$ foam results are mixed, with technical suc- cesses alternating with failures. A thorough evaluation of the economics of $\mathrm{CO}_{2}$ foam field tests is not possible using the existing published data despite encouraging preliminary results [11]. Some technical comments are, however, appropriate at this stage.

All except one of the $\mathrm{CO}_{2}$ injection projects reviewed attempted miscible displacement of residual oil after waterflooding. At the pressures involved, $\mathrm{CO}_{2}$ density is closer to that of the reservoir oil than with any other gas, while its viscosity is still low. Gravity override is therefore expected to be less of a problem while poor areal sweep and channeling are at least as worrisome. The presence of large amounts of water from waterflooding or injected as WAG cycles attempting to improve $\mathrm{CO}_{2}$ sweep must also be taken into account as a complicating factor. The acidic nature of a $\mathrm{CO}_{2}$-rich environment also imposes chemical constraints on foamers. In compensation, temperatures in $\mathrm{CO}_{2}$ projects are usually moderate, allowing the use of a broader variety of surfactants than with steam.

While steam injection is typically conducted in small spacing patterns and relatively thick sands, $\mathrm{CO}_{2}$ injection is most often run in thinner reservoirs with a much larger spacing between wells. The reservoir aspect ratio,

$$
R_{A}=\frac{H}{L} \sqrt{\frac{k_{h}}{k_{v}}}
$$

where $\mathbf{H}=$ pay thickness and $\mathrm{L}=$ interwell distance, can be used to generalize the geometric constraints in which the in principle general foam processes are appled. In going from steam to $\mathrm{CO}_{2}$ floods, aspect ratio is changed from low to high. This generates an important technical distinction in terms of foam propagation and its effect on conformance improvement. While a near-well foam bank may be effective in diverting injected steam at low aspect ratio, it can be inadequate to provide significant conformance improvement in a high aspect ratio $\mathrm{CO}_{2}$ flood. The problem is exacerbated by vertical communication, presence of fractures, and the greater channeling tendency of $\mathrm{CO}_{2}$ and other non-condensible gases that lack the self-regulation mechanisms such as heat transfer and condensation that limit fingering and channel growth with steam. Some brief comments on each $\mathrm{CO}_{2}$ foam project evaluated are given below.

\section{Rock Creek}

This early $\mathrm{CO}_{2}$ foam pilot was essentially a proof-ofconcept test $[12,13]$. It showed that co-injecting foamer solution and $\mathrm{CO}_{2}$ was possible (though it was difficult to maintain a set foam quality), and $\mathrm{CO}_{2}$ injectivity was reduced as foam was generated in the reservoir. No oil bank was detected in the lone observation well. This particular field was a notorious non-performer to several IOR methods, and the foamer used has since been rated "poor" in a comparison study [14] so there are at least two good reasons for the meagre success. Also, operational problems plagued the project and disrupted test design and monitoring. 


\section{Wilmington}

This was an attempt to divert injected $\mathrm{CO}_{2}$ in an immiscible project [15]. The same foamer was used here as at Rock Creek. Despite that fact, gas was sucessfully diverted and conformance near the injector improved. As foam was used in only one of ten injectors, evaluation of the effect of the treatment is difficult as the surrounding producers were affected by other injectors. One point worth noting is that the foam bank was dissipated during the water injection part of the WAG cycle. In our opinion, water injection into a foam bank is useful only if it contains enough foamer to regenerate foam or transport foamer deeper into the reservoir.

\section{SACROC}

An unsucessful test of foam in a carbonate reservoir was performed at SACROC, a large and well documented $\mathrm{CO}_{2}$ flood area [16]. Whether the failure was due to the poor foamer used, the same as in both above tests, or to the presence of fractures, is open to question.

\section{Rangely}

The foamer used in this project was rated as intermediate [14]. $\mathrm{CO}_{2}$ injectivity was reduced and stayed reduced for two months after four treatments, and the performance of at least one offset producer was improved. Vertical conformance was not monitored; $c f$. the comments above about $\mathrm{CO}_{2}$ density and gravity override.

\section{Wertz Tensleep}

Two foamers, ranked as intermediate and good in ref. [14], were used to divert $\mathrm{CO}_{2}$ away from thief zones and fractures. Foam placement was done using an innovative "pressure transient method" attempting to allow foamer to contact highly permeable zones first. Reduced injectivity and channeling was obtained and maintained for 2 to 8 months. Oil production response was detected after 8 months. Unfortunately, and for reasons unrelated to the foam project, the field was shut down at this stage. Despite this, the test can be classified as a technical success. In contrast to the foam tests in the similar Rangely reservoir, the effects of foam were more persistent and did not start dropping off as soon as foamer injection was discontinued. This is believed to be due to formation of stronger foams as well as better placement.

\section{North Ward-Estes}

This test attempted to divert $\mathrm{CO}_{2}$ from thief zones [11]. The foamer used is ranked intermediate in ref. [14]. Strong foam was formed and lasted 1 to 6 months. $\mathrm{CO}_{2}$ was diverted from thief zones to unswept regions and incremental oil was produced as a result of improved sweep efficiency. This project was a small scale technical and economic success. The cost for $\mathrm{CO}_{2}$-foam incremental oil over $\mathrm{CO}_{2}$ flood alone was calculated at
$\$ 2.24$ per bbl oil. However, in the same reservoir, WAG was not profitable because of high $\mathrm{CO}_{2}$ throughput.

\section{Joffre Viking}

$\mathrm{CO}_{2}$ injected into this medium- to high-permeable sandstone lens reservoir contacted only the upper third of the formation, with segregated flow as close to the injector as $15 \mathrm{~m}$. A foam pilot was done to attempt reducing gravity override by in-depth foam propagation $[17,18]$. The test pattern was nearing the end of its economic life. In injectivity tests, bottomhole pressure increased with $\mathrm{CO}_{2}$ /foamer injection; unfortunately this was followed by water injection which caused rapid pressure decline. A more extensive field test was initiated, using 10 tons of surfactant (at $0.2 \%$ ) coinjected with $\mathrm{CO}_{2}$ after a $0.5 \mathrm{wt} \%$ surfactant preflush (1 ton at $0.5 \%$ ). The bottom hole pressure increased for three weeks and reached a plateau which held for more than three months. This was interpreted as foam not propagating, but may also have been due to the complex foam mobility vs. velocity behavior. The GOR of the pattern producers did not change, and tracer results showed no significant flow improvement by the foam. Model experiments and simulations of trying to solve a similar problem with surfactant slug injection followed by gas [19] suggests that foam may not have reached the very top of the reservoir, so that gas could still finger through near the well.

\section{East Vacuum}

This test, a four-year project started late 1989 and jointly funded by the US DOE, the state of New Mexico and the field owners, has been well documented [20-25]. The foamer chosen was ranked as "good" at relevant conditions [14], and extensive further laboratory studies confirmed its suitability for the field $[20,23]$. The objective of this test is to divert injected $\mathrm{CO}_{2}$ from highpermeability zones and reduce breakthrough at the producers. Only near-well effects were expected due to surfactant adsorption [21], despite injection of a sacrificial slug. Rapid foamer solution slugs alternating with gas caused an increase in injection pressure, showing foam generation. This increase was maintained for several months. Only a slight improvement in injection profiles was observed and only during foam injection. Oil production at the "offending" well with the highest $\mathrm{CO}_{2}$ cut prior to treatment improved significantly, and some oil production improvement was seen also in two other producers. No attempt to optimize surfactant volumes was made. From 1994, after completing the pilot, the operator planned to continue injecting at much lower foamer concentrations to address this point.

In summary, the field experience indicates that foam used with $\mathrm{CO}_{2}$ can affect injectivity and give modest diversion, but evidence for efficient profile correction is less convincing. Positive effects may be correlated with increasing volumes of foamer used and times of treatment. It is possible that designing for more definite 
blockage/diversion effects by the use of stronger foams could prove more efficient than the more common approach of trying to optimize flowing $\mathrm{CO}_{2}$ mobility based on foam flow concepts, which may in some cases have led to insignificant foam effects in the reservoir.

\section{Foam in $\mathrm{HC}$-gas and $\mathrm{N}_{2}$ injection}

Only four cases of this are documented in the open literature and, although some more are known to exist, the volume of experience is even less than for $\mathrm{CO}_{2}$ foam. Foam has been used with hydrocarbons or $\mathrm{N}_{2}$ in sandstone and carbonate reservoirs, light oils, thin and massive reservoirs. Foam injection periods have generally been short.

\section{Siggins}

The first of all known foam reservoir pilots was done injecting air in this shallow sandstone field [26]. Several key foam concepts were proven, including reduced gas and water injectivity (in coinjection), the ability of foam to stop severe gas channeling, and transport of foamer (though not foam) up to $450 \mathrm{~m}$ from the injector.

\section{Two Canadian tests}

Two pilots in Alberta of foam used for hydrocarbon gas mobility control in thin reservoirs with rather large (for onshore conditions) well spacing, developed by hydrocarbon gas and WAG are published. At Pembina, gas and foamer solution was coinjected into a sand only $1 \mathrm{~m}$ thick. Oil production increased (from a low level) soon afterwards [27]. However, gas injection rates had to be cut as fracturing pressure was approached. Oil production nevertheless stayed above the baseline for five months. Similarly, when injecting foam in the somewhat thicker, limestone Kaybob reservoir, injectivity problems were also seen that led the operator to stop the foam trials after six months. Still, foam gave efficient injectant profile correction and a longer water cycle after foam washed out the foam with no permanent loss of injectivity [28]. And, a year later, effects of foam were seen in producers as lower GOR and higher oil rate. It would appear that foam, in such thin reservoirs, might be more beneficial if confined in the near well area as a practical replacement for WAG injection.

\section{Painter}

A pilot at this field in Wyoming involved the use of foam to try to control channeling of injected gas in a light oil reservoir on $\mathrm{N}_{2}$ flood. The Painter reservoir is a massive tight sandstone suffering gas coning in dualcompletion wells. The foam test was unsucessful because of a series of problems which, for once, were fully reported and discussed [29]. The foamer screening may not have been adequate. The lab tests reported were done as bulk foam shake tests (inadequate to describe foam in porous media) and flow through glass bead packs (not representative of the tight Painter rock). The foamer chosen was then flowed, apparently without effect, through a Berea core at $0.3 \%$ concentration. However, experiments on two sets of cores from the field showed mobility reduction and some flow diversion from the foam. The size and extent of flow channels around the pilot well were not known prior to the test. A $60 \%$ quality preformed foam was injected, probably causing overpressure in the well. As a result, channels may have widened or opened between the injection and production intervals. The foam test was thus negative. Foam is probably not an efficient diverting agent in such a low permeability system; also, the use of preformed foam in complex multiple completion wells can be risky compared to separate injection of foamer solution and gas. Injection of low mobility foam close to fracturing limit is unwise and, in the words of the operator: "sucessful application of foam in future projects requires a better understanding of the reservoir and process variables". The major lessons from the Painter trial are (a) problem definition is critical, (b) foam can be an excellent fracturing fluid, whether intentional or not, and (c) injection of preformed foam may carry a risk of well damage.

In summary, the few documented tests of foam used to control injected hydrocarbon gas span widely varying reservoir conditions. Foam effects are stronger than with $\mathrm{CO}_{2}$, but can cause too low injectivity so perhaps preformed foam injection or coinjection should be avoided in favor of injecting slugs of foamer solutions and gas. The production-side effects of foam may be nearly instant as at Pembina, or take years, with no correlation to well spacing. A less well described beneficial effect of foam is to prevent drops in injection pressure that may occur when injectant channels through to producers in thief zones. In miscible or near-miscible cases, foam can thus help maintaining good microscopic displacement process efficient in addition to its effects on sweep and reduced gas throughput. The case is valid also for many $\mathrm{CO}_{2}$ floods.

\section{Production well foam treatments}

With surprisingly few literature cases prior to 1990 , oil wells producing at high GOR are a major foam application target in some oil-producing areas, including the North Sea [1]. Many wells of interest are highly protific producers, and a single successful treatment can thus give a large boost in production at modest cost. A successful foam system in this kind of application must maintain strong gas blockage over extended times, essentially while static and without continuous injection of foamer, ideally in the presence of high saturations of flowing oil. Since the volumes of chemicals available are typically rather small, problem definition and targetted treatment are even more critical than in other foam processes. For the case of gas coning, requirements to placement and foam-barrier geometry have been addressed systematically $[30,31]$. 


\section{Pruadhoè Bay tests}

Production from this giant field in Alaska is limited by gas reinjection capacity. Wells that produce at high GOR are cycled or shut-in. Three different foam treatments were applied in three different high GOR wells. The foamer used was Chaser GR1080, a sulfonate blend, at $0.5 \%$ active. The two first treatments, in which surfactant solution was injected and chased by (respectively) water or gas, failed to reduce GOR and may not have created foam at all. The third test, in which a preformed foam was injected into well 15-15, was successful in reducing GOR over a period of two months.

An upper $3 \mathrm{~m}$ interval that had been giving most of the gas was treated, sealing off the remaining lower interval by a plug. 1.04 tons of $40 \%$ surfactant concentrate was injected, most of it in a $64 \mathrm{~m}^{3}$ preflush, the rest as $65 \%$ quality foam. The foam foam penetration depth was estimated at about $5 \mathrm{~m}$ into the reservoir. After some startup problems, the well produced oil for about a month at GOR's around half the maximum allowed. After a one week shut-in, a second production period of about two weeks. These positive effects are ascribed to foam reducing gas influx, although quantifying the foam bemefit relative to intermittent shut-in is harder since good baseline data are lacking.

In a previous paper [1], an explanation was proposed for the success of the third treatment but the failure of the two others. Gravity segregation was assumed to have separated the foam forming ingredients in the first two tests, but when injected as foam, they stayed together. The major lessons to learn from the Prudhoe Bay foam tests mentioned are (a) Careful process design pays, (b) Think near well fluid distribution, (c) More foamer at higher concentration may give stronger effects, (d) Chemical costs are insignificant for this type of treatment and so one can try quite expensive chemicals if they allow greater chance of success.

\section{UK North Sea pilot}

A production-well foam treatment was performed on a UK Continental Shelf (UKCS) field in July 1994. The field in question is mature and on late plateau production, with gas and water injected into its five Jurassicl Triassic reservoirs. The treated well had been completed as swing producer, but GOR rose to several times the solution value within few hours on production. The problem was interpreted as gas cusping in a $6 \mathrm{~m}$ thick high-permeable $(800 \mathrm{mD})$ sand extending into the lower gas cap. Most of the remaining $36 \mathrm{~m}$ thick oil zone had permeabilities of $300-400 \mathrm{mD}$ and most of the gas cap $50-100 \mathrm{mD}$. The temperature was $100^{\circ} \mathrm{C}$.

The foamer also used at Prudhoe Bay was selected. It was found to create only oil-sensitive foam in field core tests at reservoir conditions and thus should not risk impairing oil productivity, a prime concern in this pilot.

The treatment was designed to be a surfactant preflush followed by rapid SAG cycles. The available 3.8 tons of $40 \%$ concentrate was calculated to yield a radial penetration in the offending zone of about $6 \mathrm{~m}$. No mechanical isolation was used; the injectant was expected to enter preferentially the offending zone due to the permeability contrast. Only slight pressure buildup was seen as a result of the first injection of $71 \mathrm{~m}^{3}$ of $1 \%$ surfactant solution followed by an equal reservoir volume of gas. This was thought to indicate little generation of foam and treatment mode was changed to coinjection of $65 \%$ quality foam $\left(127 \mathrm{Rm}^{3}\right)$, which gave some pressure buildup. When the well was opened for production, the GOR increased more slowly with time than before treatment. The effect, ascribed to foam reducing gas influx, was large during the first few days after treatment and noticeable for about 14 days. Although this did pay back the costs of the foam treatment, it was not considered a success. Figure 2 sketches a possible speculative explanation. Foam was probably formed and mostly in the thief zone. However, when the well came back on production, oil could enter the foam area, killing the oil sensitive foam and leaving it open to a new gas cusp. The operator is considering how to improve the efficiency of possible future treatments, including other foam systems, larger slugs, and zone isolation during placement. As at Prudhoe, the cost of chemicals (delivered at the platform) was a minor part of treatment cost.

If the problem definition from this trial correct, the main lesson to be learned is that gas cusps may be possible to treat with a small foam volume; but a stronger and/or more oil- tolerant foam is required to maintain protection against gas in the treated area as this is invaded by oil. The risk of an efficient gas-blocking foam also reducing oil rates depends on the success of placement and well productivity in the rest of the interval.

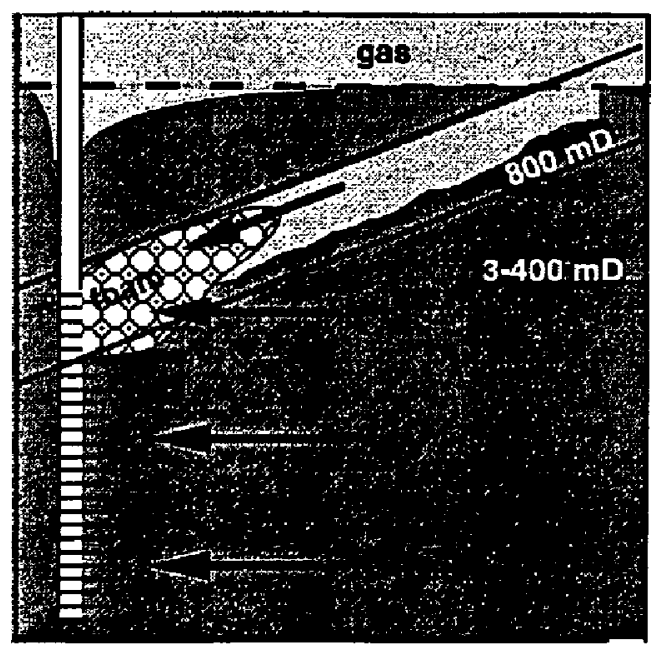

Fig. 2. Possible mode of action in UKCS foam pilot. 


\section{Norwegian North Sea pilot}

Also in mid-1994, a foam test was carried out in the Oseberg field, a major North Sea high permeable sandstone field developed by updip gas injection. This project is well described in the open literature [32-34], so only a summary is given here with some comments by the present authors.

The extremely prolific Oseberg oil producer B-27 experienced gas breakthrough in January 1994. Gas handling capacity on many Norwegian offshore fields is limited. A field pilot was done to investigate whether a nearwell foam treatment could delay the rise in GOR, reduce the gas volumes to be handled and thus prolong the useful oil-producing life of the well.

A comprehensive well logging, monitoring and production testing program was carried out and the production behavior of the well prior to foam treatment history matched by fine grid reservoir simulation. The problem was identified as a wide gas cone moving down from the descending global gas/oil contact (GOC), entering the upper production interval. It was decided to treat and produce from only this upper set of perforations, and a plug was set to shut off four lower intervals.

A foaming agent for the pilot was selected from five candidates by core screening tests and qualification tests at full reservoir conditions, using Berea and reservoir cores. The chosen foam system was a $C_{14-16} \alpha$-olefin sulfonate in sea water. At $1.0 \%$ in sea water, this gave a very low mobility foam (corresponding to a mobility reduction of several thousand) when coinjecting gas and foamer solution at $65 \%$ foam quality and a velocity of $3.5 \mathrm{~m} / \mathrm{d}$ into a $43 \mathrm{~cm}$ long 3.3 Darcy reservoir core. Next, gas was injected into this foam-filled core at a fixed pressure gradient of $0.25 \mathrm{bar} / \mathrm{m}$. The gas flow rate after 80 hours of gas injection was measured to $4 \%$ of the rate in the absence of foam. Foam performance was measured at $S_{\text {org }}$ which was $8-11 \%$ in repeat experiments, and approximately the same coinjection mobility was also measured in the same core at $S_{\text {orw }}, 27 \%$.

Alternate injection of surfactant slugs and hydrocarbon gas, starting with a gas slug, was selected as the field operating procedure. Topsides foam generation was discarded due to the complex equipment required, injectivity concerns, and risk of poor control over foam in the wellbore. Injecting a single foamer solution slug and letting the reservoir gas create foam by backproduction was discarded to avoid the risk of gravity segregation (the lower Oseberg formation has $k_{h} \approx 2-4$ Darcy and $k_{y}=0.4-2.6$ Darcy) and fears of a minimum foam generation velocity limiting the efficiency of foam creation. The injection did not follow exactly the procedure because foamer solution was slow to segregate to the perforated interval when pumped into the gas-filled wellbore. Density measurements indicate that wet foam could have formed in the wellbore. The well was shut in to allow foamer solution to segregate, after which injection was resumed. 4.33 tons of the $38 \%$ active surfactant was injected at $1.8 \%$ active matter (1.0 in the last slug). The total volumes injected were $101 \mathrm{Sm}^{3}$ foamer solution in four slugs and $35000 \mathrm{Sm}^{3}$ gas in three slugs. This was estimated to give a radial penetration of less than $10 \mathrm{~m}$. The total time from start of gas preflush to start of backproduction was 35 hours, including two 8 hour shut-in periods to allow foamer solution to reach the perforations. Apart from these, there were no problems or surprises in foam treatment or during production from the treated well. The excess pressure during injection was about 2 bar.

Production was resumed immediately after foam treatment, at an oil rate $600 \mathrm{Sm}^{3} / \mathrm{d}$. The GOR rise in the first few days of production was noticeably slower, and the stable producing GOR was reduced by $50 \%$, compared to the prefoam production tests. Careful history matching, accounting for the movement of the global GOC and the critical foam parameters, indicated that the actual GOR reduction was about $65 \%$ compared to a case without foam treatment. The GOR remained low for the duration of the test, more than six months.

In the history-matching simulations, it was noted that the value of $\mathbf{3 0}$ for the gas mobility reduction factor (MRF) with foam was much less than the laboratory values. However, if the lab data for gas injection at fixed pressure is used ( $4 \%$ of flow without foam at same $\Delta P$, or a reduction factor of 25 ), then the field and lab MRF values agree. This is also the most relevant process to describe gas flowing into and through the foam once the barrier is established. Of course, many other explanations for the discrepancy are possible. Note also that much stronger blockage of gas has been measured with foams qualified for other planned producer treatments $[35,36]$. Thus, there is potential for a still greater and/or more persistent reduction in GOR at Oseberg by using optimized foam systems. Since chemicäls cost, at about $\$ 10000$, again was only a small part of the total cost, stronger foams could bring great additional value for a modest extra investment in optimization.

The Oseberg foam pilot is a major breakthrough for treatment of production wells with foam, not least because it was successful in the difficult case of blocking gas in a well essentially being drowned by a descending gas cone. The test demonstrated that foam can significantly delay gas coning due to global GOC migration and prolong the useful oil-producing life of a well by 6 months. The economics of foam application are largely dictated by the field operating constraints. The cost, dominated by the logging and baseline production tests, could be trimmed down significantly in any ensuing commercial treatments, currently being considered by the operator.

Despite the fact that the foam used was successfully generated at residual oil, it is known that many AOS foams are sensitive to high oil saturations, especially at gas-blocking conditions ( $[37,38])$. One possible explanation for the good foam persistence that was observed in the Oseberg pilot is sketched on Figure 3. The gas 
cone is drawn as engulfing almost the entire foam-containing zone, oil entering only the bottom part of the producing interval and possibly even reverse-coning into it. In this way, most of the foam around B-27 would not be contacted by flowing oil and its oil tolerance therefore irrelevant. The high productivity allows a small part of the interval to give the oil rates obtained; in fact, before treatment the upper half of the $6.8 \mathrm{~m}$ interval was found to produce only gas. If the (highly speculative) flow picture in Figure 3 is correct, it also means that particular caution should be used in extrapolating the B-27 results to other cases where this favorable arrangement is not possible, such as the UK producer treatment just discussed.

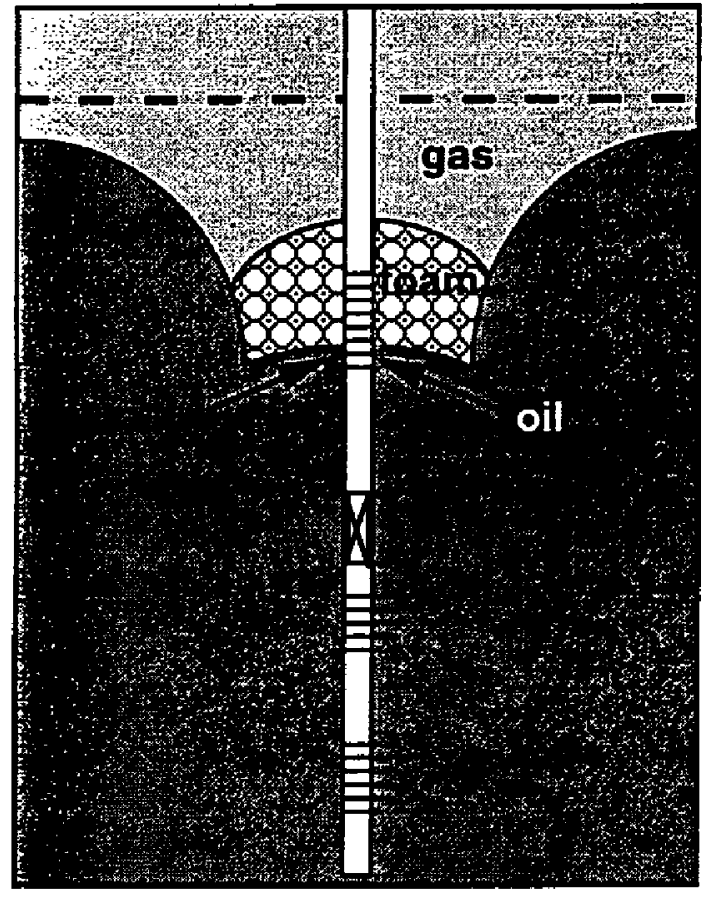

Fig. 3. Possible mode of action of foam barrier at Oseberg foam pilot.

\section{Foam for water-sweep control}

Scattered reports, mostly from Russian and Chinese sources [39] indicate that foam used for water sweep control may be practicable in many cases. The effect must rely on the well known ability of foam to reduce effective water permeabilities through the low water saturation in the foam. Foam used in this way could be cheaper than gel and less sensitive to mineralogy and chemical parameters. Note that this is the least explored foam application and the field mechanisms of action are speculative.

\section{Conclusions/Recommendations}

1. Problem definition is crucial and if lacking easily the most important cause of trouble. Essentially all cases where the problem was properly identified and the foam process mechanisms in the reservoir undèrstood, experienced successful foam treatment. Exceptions are limited to cases of direct channeling and/or where product selection was insufficient.

2. The scope of foam application has progressively in. creased from its limited base on heavy oil/thermal processes, to encompass all gases (injected and produced), but foam is still immature with anything but steam.

3. Effects on gas mobility resulting from a single foam treatment were seen in several projects of widely different character to last for periods of order six months.

4. Placement of foam is critical for success and proper placement requires a thorough understanding of near-well area reservoir properties, including gravity segregation effects. Different placement options may apply to different reservoirs even if the same prob. lem is diagnosed.

5. Selection of foamers is both field- and process-sensitive. The product selection method should take proper account of the field process intended. For example, products for use in a producer treatment should not be qualified by coinjection core flow tests alone. Conversely, for qualifying foam processes for field use, a given foamer may possibly be qualified for an injector treatment by a successful small-scale producer treatment, but the opposite may be risky.

6. The reservoir aspect ratio is a useful parameter in comparing foam experience from widely different cases. In steam or gas drive, it appears that foam cannot be efficiently propagated from injector to proucer (although foamer solution and gas may propagate separately). Foam will propagate only if the aspect ratio is large as in thick sands with narrow well spacing.

7. Some main avenues to closing the gap from research to field application of foam with the wide variety of gases of interest are:

- improving the problem understanding through measures such as proper use of suitable reservoir evaluation techniques (logging, tracers, pressure transient tests, seismics etc.) coupled with better history matching (both in terms of reservoir description and foam description) of the performance of the test area prior to and after foam treatment.

- improved representation of foam effects in reservoir simulators

- better documentation of pilot tests, including failures

- stronger foams, oil tolerant and possibly fortified by adding polymers or gelants. Note that nobody has ever yet used a strong, oil resistant foamer in the field. 


\section{Acknowledgments}

The authors would like to thank the Fulbright Foundation, the Foam subprogram of RUTH (a Norwegian industry- and state-sponsored IOR program), and RF - Rogaland Research for co-funding a 6 month stay for $\mathrm{L}$. M. Castanier as a visiting researcher at RF. Thanks also to the authors of many of the references quoted for useful discussions and explanations. Note that all explanations and speculations given are the sole responsibility of the authors and do not carry any implication of agreement by the individuals or companies referenced.

\section{References}

1. J. E. Hanssen, T. Holt, and L. M. Surguchev: "Foam Processes." Paper SPE/DOE 27768 at 9th SPE/DOE Symposium on Enhanced Oil Recovery, Tulsa 1994.

2. L. M. Castanier and W. E. Brigham: "Critique of a steam-foam pilot". Paper at DOE/NIPER Symposium on Field Application of Foams for Oil Production, Bakersfield 1993.

3. L. Castanier: "Steam with additives: Field projects of the '80s." Journal of Petroleum Science \& Engineering, 2: 1989, 193-206.

4. G. S. Kular, K. Lowe, and D. Coombe: "Foam application in an oil sands steamflood process." Paper $S P E$ 19690 at 64th SPE Annual Technical Conference and Exhibition, San Antonio 1989.

5. N. F: Djabbarah et al.: "Laboratory design and field demonstration of steam diversion with foam." Paper SPE 20067 at 60th SPE Caolifornia Regional Meeting, Ventura 1990.

6. J. M. Alvarez et al.: "Cyclic steam injection with foam: Interpretation of field test results". Paper FS 6 presented at NIPER/DOE Symposium on Field Application of Foams for Oil Production, Bakersfield 1993. DOE

7. S. S. Mohammadi. D. A. Coombe, and V.M. Stevenson: "Test of steam-foam process for mobility control in South Casper Creek reservoir." Journal of Canadian Petroleum Technology, 32: 10, 1993, $49-54$.

8. E. C. Lau, P. R. Sander, and G. J. Clark: "Steam-foam diversion process developed to overcome steam override in Athabasca". Paper at 66th SPE Annual Technical Conference and Exhibition, Dallas 1991.

9. R.L Eson and R.W. Cooke: "A comprehensive analysis of steam foam diverters and application methods". Paper SPE 18785 presented at SPE Califormia Regional Meeting, Bakerstield 1989.

11. S. I. Chou et al.: " $\mathrm{CO}_{2}$ foam field trial at North WardEstes." Paper SPE 24643 at 67 th SPE Annual Technical Conference and Exhibition, Washington, DC 1992.

12. J.P. Heller, D.A. Boone, and R.J. Watts: "Field Test of $\mathrm{CO}$, Mobility Control at Rock Creek." Paper SPE 14395 at 60ih SPE Annual Technical Conference and Exhibition, Las Vegas 1985.

13. J. P. Heller and R. J. Watts: "Two field tests of $\mathrm{CO}_{2}$ foam". Paper FS 13 at DOENIPER Symposium on Field Application of Foams for Oil Production, Bakersfield, CA 1993.

14. J. Prieditis and G. S. Paulett: " $\mathrm{CO}_{2}$-foam mobility tests at reservoir conditions in San Andres cores." Paper
SPE/DOE 24178 at 8th SPEDOE Symposium on Enhanced Oil Recovery, Tulsa 1992.

15. L.W. Holm: " $\mathrm{CO}_{2}$ Diversion using Foam in an Immiscible $\mathrm{CO}_{2}$ Field Project." SPE RE 3: February
1988. 112-118.

16. D.H. Smith: "Injectivity and Surfactant-Based Mobility Control - Field Tests," in Surfactant-Based Mobility Control, D.H. Smith, Editor. ACS Symp. Ser., 373. ACS. Washington DC 1987, pp. 429-438.

17. D. J. Stephenson, A. G. Graham, and R. W. Luhning: "Mobility control experience in the Joffre Viking miscible $\mathrm{CO}_{2}$ flood." SPE Reservoir Engineering, 8: 3 1993, 183-188.

18. D. J. Stephenson, A. G. Graham, and R. W. Luhning: "Mobility control experience in the Joffre Viking miscible $\mathrm{CO}_{2}$ flood". Paper at 6th European Symposium on Improved Oil Recovery, Stavanger 1991. pp. 301-317.

19. J.E. Hanssen, L.M. Surguchev, I. Svorstøl, and T. Blaker: "SAGA Injection: A new combination IOR pro* cess for stratified reservoirs," in New Developments in Improved Oil Recovery, H.J. De Haan, Editor. Geological Society Special Publication, 1995, pp. 111 123.

20. F. D. Martin, et al: " $\mathrm{CO}_{2}$ foam field verification test at EVGSAU injection project, Phase I: Project planning and initial results." Paper SPEDOE $24 I 76$ at SPE/DOE 8th Symposium on Enhanced Oil Recovery, Tulsa 1992.

21. J. E. Stevens et. al.: " $\mathrm{CO}$, foam field verification test at EVGSAU injection project, Phase II: Foam injection design and operating plan." Paper SPE 24642 presented at. 67 h SPE Annual Technical Conference and Exhibition, Washington, DC 1992.

23. J. P. Heller et al.: " $\mathrm{CO} 2$ foam field verification pilot test at EVGSAU: Phase IIIA - Surfactant performance characterization and quality assurance." Paper SPE/DOE 27785 at 9th SPE/DOE Symposium on Enhanced Oil Recovery, Tulsa 1994.

24. J. E. Stevens and F. D. Martin: "CO2 foam field verification pilot test at EVGSAU: Phase IIIB - Project operations and performance review." Paper SPEDOE 27786 at 9th SPEDOE Symposium on EOR, Tulsa 1994.

25. K. T. Harpole, W. T. Siemers, and M. G. Gerard: "CO2 foam field verification pilot test at EVGSAU: Phase IIIC - Reservoir characterization and response to foam injection." Paper SPE/DOE 27798 at $9 t h$ SPE/DOE Symposium on EOR, Tulsa 1994.

26. L.W. Holm: "Foam Injection Test in the Siggins Fieid, Illinois." JPT, December 1970, 1499-1507.

27. P. Matsalla, J. Chad, and J.J. Novosad: "Foam-Forming Surfactants in Pembina/ Ostracod 'G' Pool." Paper 88$39-40$ at 39 th Annual Technical Meeting of the Petroleum Society of CIM, Calgary 1988.

28. G.J. Besserer and P.C. Liu: "Application of Foam Injection in Triassic Pool, Canada: Laboratory and Field Test Results." Paper SPE 18080 at SPE 63rd Annual Technical Conference and Exhibition, Houston 1988.

29. D.L. Kuehne et al.: "Design and Evaluation of a Nitrogen-Foam Field Trial." JPT, 42: April 1990, 504512.

30. S. Ekrann and J.E. Hanssen: "Well treatments against gas coning must exploit gravity effects". Paper $F S I I$ at DOENIPER Symposium on Field Application of Foams for Oil Production, Bakersfield, CA 1993.

31. S. Ekrann: "On the protection against coning provided by horizontal barriers of limited lateral extent". Paper at Gih European Symposium on Improved Oil Recovery, Stavanger 1991. Proc., vol. IIl pp. 169-178. 
32. M. G. Aarra and A. Skauge: "A foam pilot in a North Sea oil reservoir: Preparation for a production well treatment." Paper SPE 28599 at 69 th SPE Annual Technical Conference and Exhibition, New Orleans 1994.

33. M. G. Aarra et al.:: "A foam pilot aimed at reducing gas inflow in a production well at the Oseberg field". Paper at 8th European Symposium on Improved Oil Recovery. Vienna 1995.

34. L. M. Surguchey et al.: "Modelling and history matching of foam field pilot, Oseberg field". Paper at $8 t h$ European Symposium on Improved Oil Recovery. Vienna 1995.

35. J.E. Hanssen and M. Dalland: "Foam barriers for thin oil rims: Gas blockage at reservoir conditions". Paper at 6 th European Symp. on Improved Oil Recovery, Stavanger 1991. Proceedings, vol. 1 (Book I) pp. 95-104.

36. M. Dalland and J.E. Hanssen: "Foam barriers against gas coning: Gas blockage with hydrocarbon foams". Paper at 7 th European Symposium on Improved Oil Recovery, Moscow 1993. Proceedings, vol. 84, pp 99. 109. Geol. Soc. Spec. Publ., "New Devel. in Improved Oil Recovery", H. J. De Haan (ed.)

37. J.E. Hanssen and M. Dalland: "Foams for Effective Gas Blockage in the Presence of Crude Oil at Reservoir Temperature." Paper SPE/DOE 20193 at 7th SPE/DOE Symposium on Enhanced Oil Recovery, Tulsa 1990.

38. M. Dalland, J. E. Hanssen, and T. Strøm Kristiansen: "Oil interaction with foam under static and flowing conditions in porous media." Colloids Surfaces $A$ : Physicochem. Eng. Aspects, 82: 1994, 129-140.

39. N. K. Nasibov: "Use of foam to reduce watercut in wells at Peschaney-More field" Nefteprom. Delo, 5, 1970, 2325. 